\title{
Association between dopamine beta hydroxylase rs5320 polymorphism and smoking behaviour in elderly Japanese
}

\author{
Elakeche Ella ${ }^{1,2}$, Naomi Sato ${ }^{2,3}$, Daisuke Nishizawa ${ }^{4}$, Shinji Kageyama ${ }^{2}$, Hidetaka Yamada ${ }^{1}$, Nobuya Kurabe ${ }^{2}$, \\ Keiko Ishino ${ }^{2}$, Hong Tao ${ }^{2}$, Fumihiko Tanioka ${ }^{5}$, Akiko Nozawa ${ }^{3}$, Chen Renyin ${ }^{2,6}$, Kazuya Shinmura ${ }^{2}$, \\ Kazutaka Ikeda ${ }^{4}$ and Haruhiko Sugimura ${ }^{2}$
}

The dopaminergic brain pathway is involved in many addictive behaviours, hence represents a good candidate in the study of smoking behaviour and nicotine addiction. Dopamine beta hydroxylase (DBH) is an enzyme that catalyses the conversion of dopamine into noradrenaline. This study, the first of its kind, was done to investigate the role of $D B H$ rs5320 polymorphism in smoking behaviour of elderly Japanese. This was done by collecting blood samples from 2521 subjects with various smoking habits to genotype the $D B H$ rs5320 polymorphism. Participants also had to fill out a questionnaire containing questions regarding their lifestyles. Some of the questions were from the Fagerström Test for Nicotine Dependence (FTND) and the Tobacco Dependence Screener (TDS). It was found that male ever-smokers with AA genotype smoked less cigarettes per day than those with GG and AG genotypes. FTND scores were also lowest in male ever-smokers with AA genotype and in female ever-smokers with AG genotype. There was no correlation detected between the TDS scores and any of the genotypes. This study shows that $D B H$ rs 5320 polymorphism influences nicotine dependence.

Journal of Human Genetics (2012) 57, 385-390; doi:10.1038/jhg.2012.40; published online 19 April 2012

Keywords: addiction; dopamine beta hydroxylase (DBH); Fagerström Test for Nicotine Dependence (FTND); nicotine dependence; single-nucleotide polymorphism (SNP); smoking behaviour; Tobacco Dependence Screener (TDS)

\section{INTRODUCTION}

Dopamine beta hydroxylase (DBH) is an enzyme that catalyses the conversion of dopamine to noradrenaline in sympathetic nerves. DBH is expressed in noradrenaline-containing neurons, occurring in both membrane-bound and soluble forms. ${ }^{1}$ Because of this, noradrenaline and DBH are released together during synaptic transmission, ${ }^{2,3}$ hence they can be found in cerebrospinal fluid, and plasma or serum. The human gene encoding DBH is located on chromosome $9 \mathrm{q} 34{ }^{4}$ The $D B H$ gene is composed of 12 exons and comprises a sequence of approximately $23 \mathrm{~kb} .{ }^{5}$ Serum DBH activity of human as well as gorilla have been known to be polymorphic for the last 30 years. $^{6-9}$ This inter-individual difference in serum DBH of European population has been stated as being mostly related to a promoter polymorphism at the -1021 promoter region (C to $\mathrm{T}$, rs1611115) ${ }^{10}$ Furthermore, there are probably a few pathogenetic germline mutations of $D B H$ that explain rare congenital deficiency. The amino-acid substitutions from Asparaginate to Glutaminate at codon 100 in the exon 2 of DBH (300C-A transversion), from Valine to Methionine at codon 87 in the exon 1 of DBG (259 G-A transition) and from Asparaginate to Asparagine at codon 331 in the exon 6 (991 G-A transition) together with splice site mutation (IVS1DS, T-C, $+2)$ are known. ${ }^{11,12}$ Clinical phenotypes of these deficiencies are mainly severe orthostatic hypotension and other autonomic nerve symptoms. On the other hand, other polymorphisms also have been investigated in view of a possible modulator of human conditions including psychiatric ones.

In this study, we investigated various aspects of smoking behaviour in relation to single-nucleotide polymorphism in $D B H$. The particular polymorphism investigated was the rs5320, as it was found that the minor allele frequency of this polymorphism existed in substantial number in our Japanese sample. This particular polymorphism has been shown to be associated with Parkinson's disease among North Indians, ${ }^{13}$ but our study is the first to investigate its involvement in the role of smoking behaviours.

\footnotetext{
${ }^{1}$ University of Malta Medical School, Mater Dei Hospital, Tal-Qroqq, Msida MSD, Malta; ${ }^{2}$ Department of Tumor Pathology, Hamamatsu University School of Medicine, Hamamatsu, Japan; ${ }^{3}$ Department of Clinical Nursing, Hamamatsu University School of Medicine, Hamamatsu, Japan; ${ }^{4}$ Research Project for Addictive Substances, Tokyo Metropolitan Institute of Medical Science, Tokyo, Japan; ${ }^{5}$ Department of Pathology, Iwata City Hospital, Iwata, Japan and ${ }^{6}$ Pathology Department, First Affiliated Hospital of Zhenzhou University, Henan, China

Correspondence: Dr H Sugimura, Department of Tumor Pathology, Hamamatsu University School of Medicine, 1-20-1, Handayama, 431-3192 Hamamatsu, Japan.

E-mail: hsugimur@hama-med.ac.jp

or Dr N Sato, Department of Clinical Nursing, Hamamatsu University School of Medicine, 1-20-1, Handayama, 431-3192 Hamamatsu, Japan.

E-mail: naomi25@hama-med.ac.jp
}

Received 25 January 2012; revised 6 March 2012; accepted 23 March 2012; published online 19 April 2012 


\section{MATERIALS AND METHODS}

\section{Questionnaire}

Blood was collected from 2521 subjects ( 1616 males and 905 females) between the ages of 60 and 94 years. This was done at the Iwata City Hospital during a 5 -year period from 2003 to 2008. The participants involved in this experiment had various smoking habits (1349 male ever-smokers (current-smokers and ex-smokers; $83.5 \%$ ) and 83 female ever-smokers (9.2\%)). To be eligible for this experiment, the participants had to be ambulant and be able to communicate orally. All subjects provided written consent before participating in this study. The overall portraits of subjects have been described previously. ${ }^{14}$ The participants were required to fill in a questionnaire leaflet containing various questions about lifestyle, including alcohol consumption, smoking, diet and cancer history. They were assisted in filling out the leaflet by professional interviewers. Some of the questions were from the Fagerström Test for Nicotine Dependence (FTND; a test that yields a continuous measure of nicotine dependence), ${ }^{15}$ and Tobacco Dependence Screener (TDS; a screening questionnaire for tobacco/nicotine dependence according to the International Statistical Classification of Diseases and Related Health Problems (ICD)-10, Diagnostic and Statistical Manual of Mental Disorders (DSM)-III-R and DSMIV), which consists of 10 questions. ${ }^{16}$ The questionnaire also included questions about the numbers of cigarettes smoked per day (CPD), the participants' age when they started smoking, how many times currentsmokers had tried to quit smoking and how many times ex-smokers had tried to quit smoking before succeeding.

The study design was approved by the Institutional Review Board of Hamamatsu University School of Medicine.

\section{Genotype analysis}

DNA was extracted from the blood samples given by the participants using a QIAamp DNA Blood Maxi kit according to the manufacturers' instructions (Qiagen, Hamburg, Germany). A 50 ng sample of each subjects DNA was amplified by PCR, with the primer set for $D B H$ rs5320 polymorphism using the StepOne (Applied BioSystems, Carlsbad, CA, USA). The Assay ID is C_12020332_20. Successful genotyping of DBH was performed in 100\% of the enrolled subjects. The rate of successful genotyping was almost the same as the other genotype. ${ }^{17}$

\section{Statistical analysis}

The genotype of the $D B H$ rs5320 polymorphism was tested for HardyWeinberg equilibrium using the SPSS statistics software (SPSS Japan, Tokyo, Japan). $\chi^{2}$ tests of each genotype were performed for smoking status and lung cancer history. The CPD values, FTND scores, TDS scores and trial times for quitting smoking were evaluated according to smoking status and each genotype by the Kruskal-Wallis test or Mann-Whitney $U$ test (SPSS Japan).

\section{RESULTS}

The age, sex and smoking status of the participants have been reported previously ${ }^{14}$ and are shown in Table 1. The age of participants whose DNA could be genotyped ranged from 60 to 94, with the mean age for males being 73.1 years and for females being 73.0 years. Most of the male participants $(62 \%)$ were ex-smokers, whereas most of the female participants (90.8\%) had never smoked. Current-smokers of both sexes had higher TDS than ex-smokers of both sexes. The average CPD for male current-smokers was 16.6 and for female current-smokers 12.2.

Most current-smokers were also current drinkers, and neversmokers of both sexes tended to be never-drinkers $\left(\chi^{2}=17.7\right.$, $P=0.001$ for males and $\chi^{2}=42.1, P<0.001$ for females). Table 1 also shows that ex-smokers of both sexes went through more trials to quit smoking than current-smokers.

Table 2 shows that most of the male and female participants had the GG genotype of the $D B H$ rs5320 polymorphism $(n=1275,78.9 \%$ for males and $n=693,76.6 \%$ for females), followed by the AG genotype and finally the AA phenotype (1.4\% of males and $1.3 \%$ of
Table 1 Subjects profile

\begin{tabular}{|c|c|c|c|c|}
\hline Variables & Males & P-value & Females & P-value \\
\hline Number of subjects & 1616 & & 905 & \\
\hline Mean age, years ( \pm s.d.) & $73.1( \pm 6.2)$ & & $73.0( \pm 6.4)$ & \\
\hline \multicolumn{5}{|l|}{ Age distribution, n (\%) } \\
\hline $60-64$ & $81(5.0)$ & & $51(5.6)$ & \\
\hline $65-69$ & $426(26.4)$ & & $253(28.0)$ & \\
\hline $70-74$ & $456(28.2)$ & & $240(26.5)$ & \\
\hline $75-79$ & $418(25.9)$ & & $198(21.9)$ & \\
\hline $80-84$ & $170(10.5)$ & & $134(14.8)$ & \\
\hline $85-89$ & $51(3.1)$ & & $25(2.8)$ & \\
\hline $90-$ & $14(0.9)$ & & $4(0.4)$ & \\
\hline
\end{tabular}

Smoking status, $\mathrm{n}(\%)$

$\begin{array}{lrr}\text { Current-smokers } & 345(21.3) & 30(3.3) \\ \text { Ex-smokers } & 1004(62.1) & 53(5.9) \\ \text { Never-smokers } & 267(16.5) & 822(90.8)\end{array}$

$267(16.5)$

$822(90.8)$

Mean age according to smoking status, years ( \pm s.d.)

\begin{tabular}{|c|c|c|c|c|}
\hline Current-smokers & $72.1( \pm 6.0)$ & $0.002^{\mathrm{a}}$ & $70.8( \pm 5.0)$ & $0.065^{a}$ \\
\hline Ex-smokers & $73.4( \pm 6.0)$ & & $71.8( \pm 6.4)$ & \\
\hline Never-smokers & $73.3( \pm 7.0)$ & & $73.2( \pm 6.4)$ & \\
\hline
\end{tabular}

Mean age at start of smoking, years ( \pm s.d.)

\begin{tabular}{|c|c|c|c|c|}
\hline Ever-smokers & $19.6( \pm 3.5)$ & \multirow{3}{*}{$0.298^{b}$} & $33.9( \pm 12.4)$ & \multirow{3}{*}{$0.196^{b}$} \\
\hline Current-smokers & $19.9( \pm 4.3)$ & & $36.1( \pm 13.1)$ & \\
\hline Ex-smokers & $19.6( \pm 3.2)$ & & $32.7( \pm 11.9)$ & \\
\hline
\end{tabular}

Mean numbers of CPD ( \pm s.d.)

\begin{tabular}{|c|c|c|c|c|}
\hline Ever-smokers & $21.1( \pm 13.0)$ & & $13.3( \pm 8.1)$ & \\
\hline Current-smokers & $16.6( \pm 9.1)$ & $<0.001^{b}$ & $12.2( \pm 6.0)$ & $0.604^{b}$ \\
\hline Ex-smokers & $22.7( \pm 13.7)$ & & $13.9( \pm 9.0)$ & \\
\hline
\end{tabular}

Mean numbers of $C P D \times$ years ( \pm s.d.)

\begin{tabular}{|c|c|c|c|c|}
\hline Ever-smokers & $854( \pm 582)$ & & $402( \pm 357)$ & \\
\hline Current-smokers & $852( \pm 466)$ & $0.057^{b}$ & $428( \pm 304)$ & $0.257^{b}$ \\
\hline Ex-smokers & $855( \pm 617)$ & & $386( \pm 386)$ & \\
\hline
\end{tabular}

Mean FTND score ( \pm s.d.)

\begin{tabular}{|c|c|c|c|c|}
\hline Ever-smokers & $3.58( \pm 2.20)$ & & $2.35( \pm 2.01)$ & \\
\hline Current-smokers & $3.61( \pm 2.08)$ & $0.526^{b}$ & $2.17( \pm 1.76)$ & $0.733^{b}$ \\
\hline Ex-smokers & $3.57( \pm 2.24)$ & & $2.47( \pm 2.17)$ & \\
\hline
\end{tabular}

Mean TDS score ( \pm s.d.)

\begin{tabular}{|c|c|c|c|c|}
\hline Ever-smokers & $3.07( \pm 2.48)$ & & $2.87( \pm 2.47)$ & \\
\hline Current-smokers & $3.75( \pm 2.41)$ & $<0.001^{b}$ & $3.82( \pm 2.56)$ & $0.022^{b}$ \\
\hline Ex-smokers & $2.84( \pm 2.47)$ & & $2.43( \pm 2.33)$ & \\
\hline
\end{tabular}

Mean number of trial times for quitting smoking in current-smokers ( \pm s.d.)

$$
1.36( \pm 1.64) \quad 1.24( \pm 1.55)
$$

Mean number of trial times for quitting smoking before succeeding in ex-smokers ( \pm s.d.)

Drinking status, $\mathrm{n}(\%)^{\mathrm{c}}$

$\begin{array}{lcc}\text { Current drinkers } & 853(52.9) & 178(19.7) \\ \text { Ex-drinkers } & 319(19.8) & 50(5.5)\end{array}$

Never-drinkers $\quad 442(27.4) \quad 676(74.8)$

Lung cancer history, $\mathrm{n}(\%)$

$\begin{array}{lcc}\text { Yes } & 47(2.9) & 12(1.3) \\ \text { No } & 1569(97.1) & 893(98.7)\end{array}$

Abbreviations: CPD, cigarettes smoked per day; FTND, Fagerström Test for Nicotine Dependence; TDS, Tobacco Dependence Screener.

Ever-smokers: current-smokers and ex-smokers.

aKruskal-Wallis test comparing three statuses.

buann-Whitney $U$ test comparing statuses.

Information about alcohol drinking status were obtained from 1614 male subjects and 904 female subjects. 
Table 2 Subjects distribution according to smoking status, lung cancer history and the rs5320 polymorphism of $D B H$

\begin{tabular}{|c|c|c|c|c|c|c|c|c|c|}
\hline & \multirow[b]{3}{*}{ Genotype } & \multirow{3}{*}{$\begin{array}{l}\text { Total } \\
\text { n (\%) }\end{array}$} & \multicolumn{3}{|c|}{ Smoking status } & \multirow[b]{3}{*}{ P-value } & \multicolumn{3}{|c|}{ Lung cancer history } \\
\hline & & & Current-smokers & Ex-smokers & Never-smokers & & Yes & No & \\
\hline & & & n (\%) & n (\%) & n (\%) & & n (\%) & n (\%) & P-value ${ }^{b}$ \\
\hline \multirow[t]{3}{*}{ Males } & GG & 1275 (78.9) & 277 (80.3) & $788(78.5)$ & $210(78.7)$ & & $41(87.2)$ & $1234(78.6)$ & \\
\hline & $A G$ & 319 (19.7) & $65(18.8)$ & $203(20.2)$ & $51(19.1)$ & 0.639 & $5(10.6)$ & 314 (20.0) & 0.195 \\
\hline & $A A$ & $22(1.4)$ & $3(0.9)$ & $13(1.3)$ & $6(2.2)$ & & $1(2.1)$ & $21(1.3)$ & \\
\hline \multirow[t]{3}{*}{ Females } & GG & $693(76.6)$ & $22(73.3)$ & $41(77.4)$ & $630(76.6)$ & & $7(58.3)$ & $686(76.8)$ & \\
\hline & $A G$ & $200(22.1)$ & $7(23.3)$ & $12(22.6)$ & $181(22.0)$ & 0.688 & $5(41.7)$ & $195(21.8)$ & 0.277 \\
\hline & $A A$ & $12(1.3)$ & $1(3.3)$ & $0(0)$ & $11(1.3)$ & & $0(0)$ & $12(1.3)$ & \\
\hline
\end{tabular}

The $\chi^{2}$ tests were performed based on $3 \times 3$ tables.

bThe $\chi^{2}$ tests were performed based on $3 \times 2$ tables.

Table 3 Subjects distribution according to smoking status and lung cancer history

\begin{tabular}{|c|c|c|c|c|c|c|}
\hline & \multirow[b]{2}{*}{ Lung cancer history } & \multirow[b]{2}{*}{$\begin{array}{l}\text { Total } \\
\text { n (\%) }\end{array}$} & \multicolumn{3}{|c|}{ Smoking status } & \multirow[b]{2}{*}{ P-value } \\
\hline & & & $\begin{array}{c}\text { Current-smokers } \\
\mathrm{n}(\%)\end{array}$ & $\begin{array}{c}\text { Ex-smokers } \\
\mathrm{n}(\%)\end{array}$ & $\begin{array}{c}\text { Never-smokers } \\
\mathrm{n}(\%)\end{array}$ & \\
\hline \multirow[t]{2}{*}{ Males } & Yes & $47(2.9)$ & $2(0.6)$ & $44(4.4)$ & $1(0.4)$ & $<0.001$ \\
\hline & No & $1569(97.1)$ & $343(99.4)$ & $960(95.6)$ & $266(99.6)$ & \\
\hline \multirow[t]{2}{*}{ Females } & Yes & $12(1.3)$ & $0(0)$ & $1(1.9)$ & $11(1.3)$ & 0.689 \\
\hline & No & 893 (98.7) & 30 (100) & $52(98.1)$ & 811 (98.7) & \\
\hline
\end{tabular}

The $\chi^{2}$ tests were performed based on $2 \times 3$ tables.

females). Although it may be possible that some kind of population bias exist in this rural population, we tested this genotype if it is in accordance with the Hardy-Weinberg equilibrium. Actually the genotype distribution obeyed the Hardy-Weinberg equilibrium $\left(\chi^{2}=0.179, \quad P=0.914\right.$ for males and $\chi^{2}=0.332, P=0.842$ for females). Smoking status (current-smokers, ex-smokers and neversmokers) was not significantly different between the three genotypes, nor was lung cancer history.

Table 3 shows subjects distribution according to smoking status and lung cancer history. It shows a significant relationship between lung cancer history and ex-smokers in males $(P<0.001)$; however, there was no significant relationship between the $D B H$ rs5320 polymorphism and lung cancer history in male ex-smokers. Most cases of lung cancer history occurred in male ex-smokers with GG genotype, but not statistically significant (Table 4).

The $D B H$ rs5320 polymorphism was shown to be of significance in both males and females with regard to FTND, and in males only with regard to $\mathrm{CPD}$ (Table 5). Males with AA genotype smoked less cigarettes per day, while those with GG and AG smoked similar number of cigarettes per day. Male ever-smokers with AA genotype also had lower FTND scores than those with AG and GG genotypes, while female ever-smokers with AG genotype had the lowest FTND scores.

\section{DISCUSSION}

The dopaminergic brain pathway is one that has been studied extensively in regards to addictive behaviour due to the shared characteristics of drug abuse to elicit the release dopamine. Because
Table 4 Subjects distribution according to lung cancer history and the rs5320 polymorphism of $D B H$ in male ex-smokers

\begin{tabular}{|c|c|c|c|c|}
\hline \multirow[b]{2}{*}{ Genotype } & \multirow[b]{2}{*}{$\begin{array}{c}\text { Total } \\
\text { n (\%) }\end{array}$} & \multicolumn{2}{|c|}{ Lung cancer history } & \multirow[b]{2}{*}{ P-value } \\
\hline & & $\begin{array}{c}\text { Yes } \\
\text { n (\%) }\end{array}$ & $\begin{array}{c}\text { No } \\
\mathrm{n}(\%)\end{array}$ & \\
\hline GG & $788(78.5)$ & $38(86.4)$ & $750(78.1)$ & \\
\hline$A G$ & $203(20.2)$ & 5 (11.4) & $198(20.6)$ & 0.208 \\
\hline AA & $13(1.3)$ & $1(2.3)$ & 12 (1.3) & \\
\hline
\end{tabular}

aThe $\chi^{2}$ test was performed based on $3 \times 2$ table.

of this, genes involved in dopamine metabolism represent good candidates in the study of addictive behaviours, such as smoking.

This study specifically shows a significant correlation between the CPD in males and FTND in males and females and the $D B H$ polymorphism. Males with AA genotype tend to be the least dependent on nicotine, having the lowest CPD and FTND scores, while females with AG genotype had the lowest FTND scores.

$D B H$ polymorphisms have been investigated from the standpoint of DBH deficiency, several neurological diseases, from migraine ${ }^{18}$ to attention-deficit hyperactivity disorder, ${ }^{19}$ hypertension ${ }^{20}$ and cocaine dependence. $^{21}$ The promoter polymorphism has been reported to be associated with Alzheimer's disease. ${ }^{22}$

Several polymorphisms of $D B H$ have been studied in terms of the association of smoking behaviour. Among them the promoter polymorphism $-1021 \mathrm{C} / \mathrm{T}$ ( $\mathrm{rs} 1611115$ ) is the most extensively 
Table 5 Comparison of smoking index of ever-smokers according to the rs5320 polymorphism of $D B H$

\begin{tabular}{|c|c|c|c|c|c|c|}
\hline \multirow[b]{2}{*}{ Index } & \multicolumn{3}{|c|}{ Males } & \multicolumn{3}{|c|}{ Females } \\
\hline & $n$ & Mean \pm s.d. & $\mathrm{P}$-value ${ }^{a}$ & $\mathrm{n}$ & Mean \pm s.d. & $\mathrm{P}$-value ${ }^{a}$ \\
\hline \multicolumn{7}{|c|}{ Age at start of smoking } \\
\hline GG & 1062 & $19.6 \pm 3.3$ & & 62 & $33.9 \pm 13.2$ & \\
\hline$A G$ & 268 & $19.9 \pm 4.3$ & 0.593 & 19 & $33.9 \pm 10.1$ & 0.949 \\
\hline$A A$ & 16 & $20.4 \pm 3.0$ & & 1 & 35.0 & \\
\hline \multicolumn{7}{|l|}{$C P D$} \\
\hline GG & 1065 & $21.3 \pm 13.1$ & & 63 & $13.8 \pm 8.4$ & \\
\hline$A G$ & 268 & $20.9 \pm 12.5$ & 0.007 & 19 & $11.2 \pm 6.6$ & 0.389 \\
\hline$A A$ & 16 & $13.4 \pm 6.1$ & & 1 & 20.0 & \\
\hline \multicolumn{7}{|c|}{$C P D \times$ years } \\
\hline GG & 1061 & $862 \pm 598$ & & 62 & $419 \pm 377$ & \\
\hline$A G$ & 268 & $840 \pm 528$ & 0.055 & 19 & $334 \pm 289$ & 0.557 \\
\hline$A A$ & 16 & $549 \pm 226$ & & 1 & 620 & \\
\hline \multicolumn{7}{|l|}{ FTND } \\
\hline GG & 983 & $3.62 \pm 2.23$ & & 57 & $2.60 \pm 2.02$ & \\
\hline$A G$ & 251 & $3.53 \pm 2.07$ & 0.044 & 19 & $1.53 \pm 1.84$ & 0.030 \\
\hline$A A$ & 15 & $2.20 \pm 1.42$ & & 1 & 4.00 & \\
\hline \multicolumn{7}{|l|}{ TDS } \\
\hline GG & 934 & $3.08 \pm 2.47$ & & 51 & $2.94 \pm 2.48$ & \\
\hline$A G$ & 229 & $3.10 \pm 2.57$ & 0.215 & 17 & $2.59 \pm 2.58$ & 0.692 \\
\hline$A A$ & 15 & $1.87 \pm 1.46$ & & 1 & 4.00 & \\
\hline \multicolumn{7}{|c|}{ Times of trial for quitting smoking in current-smokers } \\
\hline GG & 276 & $1.37 \pm 1.68$ & & 17 & $1.38 \pm 1.69$ & \\
\hline$A G$ & 64 & $1.34 \pm 1.48$ & 0.415 & 7 & $0.71 \pm 1.11$ & 0.557 \\
\hline AA & 3 & $0.33 \pm 0.58$ & & 1 & 2.00 & \\
\hline \multicolumn{7}{|c|}{ Times of trial for quitting smoking before succeeding in ex-smokers } \\
\hline GG & 698 & $2.10 \pm 1.54$ & & 35 & $1.74 \pm 1.28$ & \\
\hline$A G$ & 182 & $2.12 \pm 1.52$ & 0.916 & 12 & $1.42 \pm 1.17$ & 0.317 \\
\hline$A A$ & 12 & $2.17 \pm 1.59$ & & 0 & $-{ }^{b}$ & \\
\hline
\end{tabular}

aKruskal-Wallis test.

bNot applicable.

investigated as Zabeitian et al. ${ }^{23}$ reported this polymorphism as a functional polymorphism explaining inter-individual difference of plasma DBH activity. As to its possible association with smoking behaviour, Freier et al. ${ }^{24}$ reported that individuals who had at least one $D B H-1021 \mathrm{~T}$ allele smoked fewer cigarettes per day than CC homozygotes in relatively small numbers of the European smokers $(n=220)$. Another polymorphism, DBH polymorphism T1368A (rs77576840), has been shown to be associated with cigarette consumption. . $^{25}$

The tobacco and genetics consortium did a meta-analysis totalling 74053 subjects and found $D B H$ rs $3025343[\mathrm{G}]$ is associated with smoking cessation. ${ }^{26}$ Siedlinski et al. ${ }^{27}$ reported the genome-wide study of chronic obstructive pulmonary disease. They could replicate the result by the above consortium; that is, there was an association between a candidate genotype rs3025343 and smoking cessation in their subjects. The other polymorphisms of $D B H$ have been also attempted to correlate with smoking. For example, the rs77905 was investigated in terms of the association with smoking status and nicotine level in 1518 adolescent subjects in United Kingdom, but no association was found. ${ }^{28}$ Actually, Breitling et al. ${ }^{29}$ reported this rs77905 polymorphism did not influence smoking cessation programme including 577 heavy smokers.

The rs5320 polymorphism of $D B H$ was investigated as haplotype analysis of Parkinson's disease. Haplotypes rs1611115T $>\mathrm{C}-$ rs1108580A $>$ G-rs5320A $>$ G-rs129882C $>$ T are reported to be associated with Parkinson's disease. ${ }^{13}$ Our findings that $D B H$ rs5320 genotype are associated with smoking behaviour remind us of a wellknown observation that Parkinson's disease is less prevalent in smokers and there may be a common genetic root for these status, Parkinson's disease and (addicted) smoking. ${ }^{30-32}$ Haplotype block structure of Japanese and Han Chinese population is shown in the Figure 1. Actually, this haplotype block indicates the relatively strong linkage $\left(r^{2}=0.63\right)$ between rs1108589 and rs5320. Among the singlenucleotide polymorphisms mentioned above, the rs77576840 is not so common and is not listed in the HapMap database. It is between rs302530 and rs1108580. The rs3025343 is outside the figure covers (far $5^{\prime}$ upstream).

As shown previously, numerous polymorphic sites of $D B H$ were investigated in various populations. We picked up rs5320 because the prevalence in Japanese is feasible and this is a non-synonymous variation. These polymorphic sites including rs5320 are linked with each other depending on populations. Most of them do not have mechanistic rationale for why these polymorphisms are apparently associated with smoking behaviour, which awaits further investigation. The polymorphism at rs5320, G allele in GCG (Ala) vs A allele in ACG (Thr) at the position 211 of this protein may not have a severe biological effect probably, considering these two amino acids exist alternatively from each other in some of the primates (Figure 2). In regard to our result that males with AA genotype had the lowest $\mathrm{CPD}$ and FTND score, the reason why this A allele behaves in a recessive manner is unknown. Effect of amino-acid substitution may influence only when both alleles are variants. An exploration on functional rationale would be warranted.

Interestingly, unlike the FTND scores, no relation was found between the TDS and any of the rs5320 allelotype in our study. This could be due to the fact that the traits detected by the scores of the FTND and TDS are different from each other. ${ }^{33}$ Smoking is a personal behaviour that can be attributed to many genetic and environmental factors. The questions in the FTND detect the physical aspects of nicotine dependence, including the one on the value of CPD, whereas those in the TDS tend to focus on the mental aspects of smoking. The TDS is a questionnaire for screening tobacco/nicotine dependence according to some criteria of mental disorder. These characteristics of scales may have led to the result that the CPD and FTND, not TDS in males, were related to the $\mathrm{DBH}$ polymorphism significantly. Regarding female subjects, the number of smoker with AA genotype was only one, so the relations between the FTND and this polymorphism should be examined further.

Limitations of this study and its interpretation include the fact that the participants were recruited from a rural city, where demographical and occupational characteristics are different from those living in urban cities or agricultural communities. To validate our observations, replication of this study would need to be done with larger and different populations. This would allow for a larger representation of the various genotypes associated with the $D B H$ rs5320 polymorphism and also a larger female sample size, so that one can be able to make a clearer conclusion whether the AA genotype of this locus corresponds 


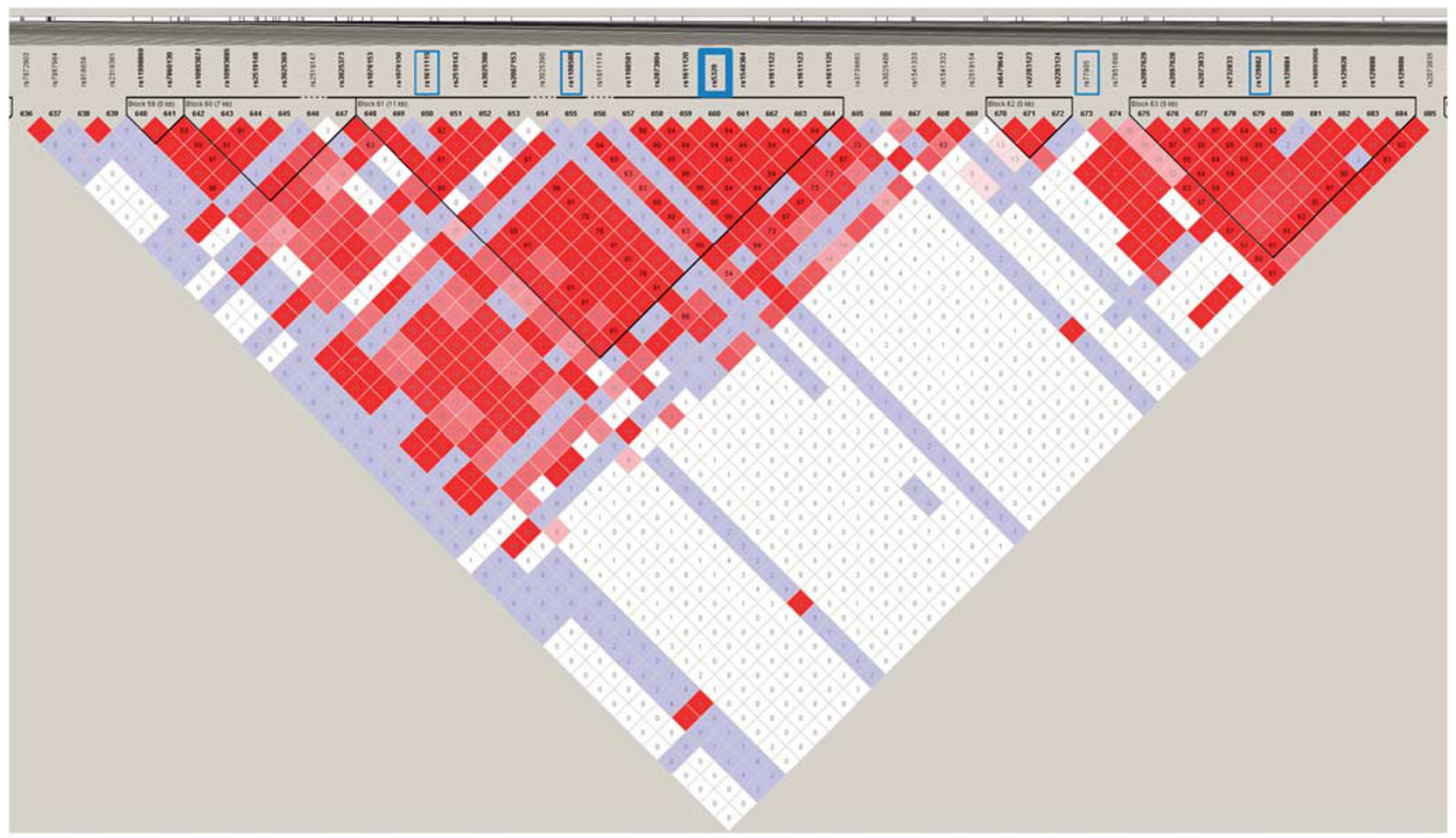

Figure 1 The state of linkage disequilibrium (LD) between the single-nucleotide polymorphisms in the region around the rs 5320 polymorphism, which is shown in thick rectangle. The rs1611115, rs77905, rs129882 and rs 1108580 are shown in thin rectangles. The strength of LD was calculated based on the genotype data of the Japanese and Han Chinese population extracted from the position 135,474,113 to 135,522,004 on chromosome 9 in the Hapmap database (http://hapmap.ncbi.nlm.nih.gov/index.html.ja). ${ }^{34}$ Numbers in squares represent percentage of the $r^{2}$ values. Squares without numbers represent $r^{2}=1$. The colour scheme was according to the 'Standard Color Scheme' of the Haploview v.4.1 software (Lod $\geqslant 2, D^{\prime}=1:$ bright red; Lod $\geqslant 2$, $D^{\prime}<1$ : shades of pink/red; Lod $<2, D^{\prime}=1$ : blue; Lod $<2, D^{\prime}<1$ : white). ${ }^{35}$ The LD blocks were defined based on the default algorithm by Gabriel et al. ${ }^{36}$

\begin{tabular}{|c|c|c|c|}
\hline Homo sapiens & $P S D$ & $\mathrm{~A}$ & \\
\hline Pan troglodytes & $P S D$ & A & \\
\hline Pongo abelii & $P S D$ & $\mathrm{~T}$ & \\
\hline Nomascus leucogenys & $P S D$ & $A$ & \\
\hline Macaca mulatta & $P S D$ & $\mathrm{~T}$ & \\
\hline
\end{tabular}

rs5320, exon4

Figure 2 Amino-acid alignment surrounding the position 211 in human and the corresponding positions in the other primates. Though the information on genetic polymorphism in the primates is limited, the database shows this position is Ala or Thr in several primates including human being.

with having a higher FTND score. Recruitment of sample population from a wider demography that is, urban cities and agricultural villages would be needed. This would take into account the different smoking characteristics. Despite these shortcomings, our data has provided a major clue in understanding the smoking behaviour of humans.

\section{CONFLICT OF INTEREST}

The authors declare no conflict of interest.

\section{ACKNOWLEDGEMENTS}

We acknowledge Dr Kimura at the Hakodate National Hospital for DBH assays. This work was supported by grants-in-aid from the Japanese Ministry of Health, Labour and Welfare for the Comprehensive 10-Year Strategy for Cancer Control and Research on international cooperation in medical science, and from the Japanese Ministry of Education, Culture, Sports, Science and Technology for priority area (221S0001), from the Smoking Research Foundation and from the 21st Century COE programme of the Hamamatsu University School of Medicine.

1 Stewart, L. C. \& Klinman, J. P. Dopamine beta-hydroxylase of adrenal chromaffin granules: structure and function. Annu. Rev. Biochem. 57, 551-592 (1988).

2 Weinshilboum, R. M., Thoa, N. B., Johnson, D. G., Kopin, I. J. \& Axelrod, J. Proportional release of norepinephrine and dopamine- -hydroxylase from sympathetic nerves. Science 174, 1349-1351 (1971).

3 Smith, A. D., De Potter, W. P., Moerman, E. J. \& De Schaepdryver, A. F. Release of dopamine beta-hydroxylase and chromogranin A upon stimulation of the splenic nerve. Tissue Cell 2, 547-568 (1970).

4 Craig, S. P., Buckle, V. J., Lamouroux, A., Mallet, J. \& Craig, I. W. Localization of the human dopamine beta hydroxylase (DBH) gene to chromosome 9q34. Cytogenet. Cell Genet. 48, 48-50 (1988).

5 Kobayashi, K. Kurosawa, Y. Fujita, K. \& Nagatsu, T. Human dopamine betahydroxylase gene: two mRNA types having different $3^{\prime}$-terminal regions are produced through alternative polyadenylation. Nucleic Acids Res. 17, 1089-1102 (1989).

6 Dunnette, J. \& Weinshilboum, R. Human serum dopamine beta-hydroxylase: correlation of enzymatic activity with immunoreactive protein in genetically defined samples. Am. J. Hum. Genet. 28, 155-166 (1976). 
7 Dunnette, J. \& Weinshilboum, R. Inheritance of low immunoreactive human plasma dopamine-beta-hydroxylase. Radioimmunoassay studies. J. Clin. Invest. 60, 10801087 (1977).

8 Dunnette, J. \& Weinshilboum, R. Family studies of plasma dopamine-beta-hydroxylase thermal stability. Am. J. Hum. Genet. 34, 84-99 (1982).

9 Dunnette, J. H. \& Weinshilboum, R. M. Serum dopamine beta-hydroxylase activity in non-human primates: phylogenetic and genetic implications. Comp. Biochem. Physiol. C. 75, 85-91 (1983).

10 Cubells, J. F. \& Zabetian, C. P. Human genetics of plasma dopamine beta-hydroxylase activity: applications to research in psychiatry and neurology. Psychopharmacology (Berl) 174, 463-476 (2004)

11 Kim, C. H., Zabetian, C. P., Cubells, J. F., Cho, S., Biaggioni, I., Cohen, B. M. et al. Mutations in the dopamine beta-hydroxylase gene are associated with human norepinephrine deficiency. Am. J. Med. Genet. 108, 140-147 (2002).

12 Timmers, H. J., Deinum, J., Wevers, R. A. \& Lenders, J. W. Congenital dopamine-betahydroxylase deficiency in humans. Ann. N.Y. Acad. Sci. 1018, 520-523 (2004).

13 Punia, S., Das, M., Behari, M., Mishra, B. K., Sahani, A. K., Govindappa, S. T. et al. Role of polymorphisms in dopamine synthesis and metabolism genes and association of DBH haplotypes with Parkinson's disease among North Indians. Pharmacogenet. Genomics 20, 435-441 (2010).

14 Sato, N., Kageyama, S., Chen, R., Suzuki, M., Mori, H., Tanioka, F. et al. Association between neuropeptide $Y$ receptor 2 polymorphism and the smoking behavior of elderly Japanese. J. Hum. Genet. 55, 755-760 (2010).

15 Heatherton, T. F., Kozlowski, L. T., Frecker, R. C. \& Fagerstrom, K. O. The Fagerstrom Test for Nicotine Dependence: a revision of the Fagerstrom Tolerance Questionnaire. Br. J. Addict. 86, 1119-1127 (1991).

16 Kawakami, N., Takatsuka, N., Inaba, S. \& Shimizu, H. Development of a screening questionnaire for tobacco/nicotine dependence according to ICD-10, DSM-III-R, and DSM-IV. Addict. Behav. 24, 155-166 (1999).

17 Sato, N., Kageyama, S., Chen, R., Suzuki, M., Tanioka, F., Kamo, T. et al. Association between neurexin 1 (NRXN1) polymorphisms and the smoking behavior of elderly Japanese. Psychiatr. Genet. 20, 135-136 (2010).

18 Ghosh, J., Pradhan, S. \& Mittal, B. Role of dopaminergic gene polymorphisms (DBH 19 bp Indel and DRD2 Nco I) in genetic susceptibility to migraine in North Indian population. Pain Med. 12, 1109-1111 (2011).

19 Bhaduri, N., Sarkar, K., Sinha, S., Chattopadhyay, A. \& Mukhopadhyay, K. Study on $\mathrm{DBH}$ genetic polymorphisms and plasma activity in attention deficit hyperactivity disorder patients from Eastern India. Cell Mol. Neurobiol. 30, 265-274 (2009).

20 Chen, Y., Wen, G., Rao, F., Zhang, K., Wang, L., Rodriguez-Flores, J. L. et al. Human dopamine beta-hydroxylase (DBH) regulatory polymorphism that influences enzymatic activity, autonomic function, and blood pressure. J. Hypertens. 28, 76-86 (2010).

21 Brousse, G., Vorspan, F., Ksouda, K., Bloch, V., Peoc'h, K., Laplanche, J. L. et al. Could the inter-individual variability in cocaine-induced psychotic effects influence the development of cocaine addiction? Towards a new pharmacogenetic approach to addictions. Med. Hypotheses 75, 600-604 (2010).

22 Combarros, O., Warden, D. R., Hammond, N Cortina-Borja, M., Belbin, 0 Lehmann, M. G. et al. The dopamine beta-hydroxylase $-1021 \mathrm{C} / \mathrm{T}$ polymorphism is associated with the risk of Alzheimer's disease in the Epistasis Project. BMC Med Genet. 11, 162 (2010).

23 Zabetian, C. P., Anderson, G. M., Buxbaum, S. G., Elston, R. C., Ichinose, H., Nagatsu, T. et al. A quantitative-trait analysis of human plasma-dopamine betahydroxylase activity: evidence for a major functional polymorphism at the DBH locus. Am. J. Hum. Genet. 68, 515-522 (2001).

24 Freire, M. T., Marques, F. Z., Hutz, M. H. \& Bau, C. H. Polymorphisms in the DBH and DRD2 gene regions and smoking behavior. Eur. Arch. Psychiatry Clin. Neurosci. 256, 93-97 (2006).

25 McKinney, E. F., Walton, R. T., Yudkin, P., Fuller, A., Haldar, N. A., Mant, D. et al. Association between polymorphisms in dopamine metabolic enzymes and tobacco consumption in smokers. Pharmacogenetics 10, 483-491 (2000).

26 The Tobacco and Genetics Consortium. Genome-wide meta-analyses identify multiple loci associated with smoking behavior. Nat. Genet. 42, 441-447 (2010).

27 Siedlinski, M., Cho, M. H., Bakke, P., Gulsvik, A., Lomas, D. A., Anderson, W. et al. Genome-wide association study of smoking behaviours in patients with COPD. Thorax 66, 894-902 (2011).

28 Huang, S., Cook, D. G., Hinks, L. J., Chen, X. H., Ye, S., Gilg, J. A. et al CYP2A6, MAOA, DBH, DRD4, and 5HT2A genotypes, smoking behaviour and cotinine levels in 1518 UK adolescents. Pharmacogenet. Genomics 15, 839-850 (2005).

29 Breitling, L. P., Twardella, D., Hoffmann, M. M., Witt, S. H., Treutlein, J. \& Brenner, H. Prospective association of dopamine-related polymorphisms with smoking cessation in general care. Pharmacogenomics 11, 527-536 (2010).

$30 \mathrm{Gu}, \mathrm{Z}$., Feng, X., Dong, X. \& Chan, P. Smoking, genes encoding dopamine pathway and risk for Parkinson's disease. Neurosci. Lett. 482, 31-34 (2010).

31 Shahi, G. S. \& Moochhala, S. M. Smoking and Parkinson's disease-a new perspective. Rev. Environ. Health. 9, 123-136 (1991).

32 Wirdefeldt, K., Adami, H. O., Cole, P., Trichopoulos, D. \& Mandel, J. Epidemiology and etiology of Parkinson's disease: a review of the evidence. Eur. J. Epidemiol. 26(Suppl 1) S1-58 (2011).

33 Sato, N., Sato, T., Nozawa, A. \& Sugimura, H. Assessment scales for nicotine addiction. J. Addict. Res. Ther. doi:10.4172/2155-6105.S1-008 (2012).

34 International HapMap Consortium. A haplotype map of the human genome. Nature 437, 1299-1320 (2005).

35 Barrett, J. C., Fry, B., Maller, J. \& Daly, M. J. Haplotype analysis and visualization of LD and haplotype maps. Bioinformatics 21, 263-265 (2005).

36 Gabriel, S. B., Schaffner, S. F. \& Nguyen, H. The structure of haplotype blocks in the human genome. Science 296, 2225-2229 (2002). 